\title{
Elaboración de una bebida utilizando subproductos de la industria láctea
}

\section{(Processing a beverage using by-products of the dairy industry)}

\begin{abstract}
Maricruz Mieles Cedeño¹, Lucía D. Yépez Tamayo², Lucía Ramírez-Cárdenas³
\section{Resumen:}

La producción de suero a nivel mundial es de 180 a 190 millones de toneladas por año y genera 1.6 billones de litros de suero ácido como residuo. Ecuador destina el $40 \%$ de la producción de leche a la industrialización y a la elaboración de quesos artesanales. El suero presenta lactosa, sólidos totales, proteína, minerales y vitaminas; el suero ácido posee mayor cantidad de fósforo, ácido láctico y aminoácidos esenciales frente al suero dulce. Los nutrientes producen contaminación al generar altas cantidades de DBO y DBQ. El objetivo de este estudio fue evaluar la utilización de suero ácido y goma xanthan en la elaboración de un néctar de naranja. Se utilizó un diseño completamente al azar, con arreglo factorial $2^{2}$ (suero ácido: 10 y $15 \%$; goma xanthan: 0.05 y $0.1 \%$ ) y cuatro repeticiones. Los datos fueron examinados mediante Análisis de Varianza y prueba de Tukey (5\%). El tratamiento con $10 \%$ de suero ácido y $0.1 \%$ de goma xanthan fue el único que cumplió con las especificaciones establecidas para pH, acidez y sólidos solubles. Sensorialmente se ubicó entre "me gusta" y "me gusta mucho" (nivel de agrado del $85 \%$ ). La intención de compra mostró que el $86 \%$ de consumidores compraría el producto.
\end{abstract}

Palabras clave: suero ácido; lactosuero; goma xanthan; néctar.

\begin{abstract}
:
Worldwide whey production is 180 to 190 million tonnes per year, generating 1.6 billion liters of acid whey as waste. Ecuador allocates $40 \%$ of milk production to industrialization and to the production of artisanal cheeses. Whey contains lactose, total solids, protein, minerals and vitamins; the acid whey has more phosphorus, lactic acid and essential amino acids compared to sweet whey. Nutrients produce pollution by generating high amounts of BOD and DBQ. The objective of this study was to evaluate the use of whey acid and xanthan gum in the preparation of an orange nectar. A completely randomized design with factorial arrangement $2^{2}$ (acid whey: 10 and $15 \%$, xanthan gum: 0.05 and $0.1 \%$ ) and four replicates were used. The treatment with $10 \%$ acid whey and $0.1 \%$ xanthan gum was the only one that met the established specifications for $\mathrm{pH}$, acidity and soluble solids. Sensory was located between "I like" and "I like it very much" (level of satisfaction of $85 \%$ ). The purchase intention showed that $86 \%$ of consumers would buy the product. The data were analyzed using Analysis of Variance and Tukey's test (5\%).
\end{abstract}

Keywords: acid whey; whey; xanthan gum; nectar.

\footnotetext{
1 maricruzmielesc@gmail.com

2 luciyepez26@hotmail.com

3 Universidad San Francisco de Quito, Quito, Ecuador (Iramirez@usfq.edu.ec)
} 


\section{Introducción}

A nivel mundial se producen de 180 a 190 millones de toneladas de suero por año, eliminando la mitad de los sólidos totales presentes en la leche los que incluyen nutrientes como proteína, lactosa, minerales y vitaminas (Chandrapala et al., 2015). Muñi, Páez, Faría, Ferrer y Ramones (2005) estimaron que por cada kg de queso se producían $9 \mathrm{~kg}$ de lactosuero. En la actualidad, las compañías enfrentan un gran problema de contaminación al generar 1,6 billones de litros de suero ácido por año como residuo (Chandrapala et al., 2015). Los nutrientes presentes en el suero generan cerca de $3,5 \mathrm{~kg}$ de demanda biológica de oxígeno (DBO) y $6,8 \mathrm{~kg}$ de demanda química de oxígeno (DQO) por cada $100 \mathrm{~kg}$ de lactosuero líquido que debe degradarse, donde la lactosa es el principal componente que contribuye a la alta DBO y DQO (Muñi, Páez, Faría, Ferrer y Ramones, 2005).

El suero es un líquido que se obtiene después de la coagulación de las micelas de caseína en el proceso de cuajado de leche durante la elaboración de quesos y mantequillas (Vela, Castro, Caballero y Ballinas, 2012) y se clasifica en ácido y dulce (Chandrapala et al., 2015). El suero dulce, está basado en la coagulación enzimática (renina) de la caseína a $\mathrm{pH}$ 6,5. El ácido resulta del proceso de fermentación o adición de ácidos orgánicos o ácidos minerales para coagular la caseína como ocurre en la elaboración de quesos frescos (Jelen, 2003). Además presenta bajo contenido de proteína y lactosa y un reducido $\mathrm{pH}$; sin embargo, tiene mayor cantidad de fósforo, calcio y ácido láctico frente al suero dulce (Chandrapala et al., 2015). El suero de leche posee el más alto valor biológico de la proteína de cualquier otra fuente. Entre las proteínas más importantes se incluyen la $\beta$ lactoglobulina, $\alpha$-lactoalbúmina, seroalbúmina bovina, inmunoglobulinas y proteosas peptona; no obstante el suero ácido contiene lactoferrina, glucoproteínas, lactoperoxidasas y transferrina (Gangurde, Chordiya, Patil y Baste, 2011); se destacan los aminoácidos esenciales triptófano, lisina y aminoácidos azufrados (Londoño, Sepúlveda, Hernández y Parra, 2008). Asimismo, las proteínas de suero han sido utilizadas en diferentes alimentos, por sus propiedades funcionales como emulsificantes, espesantes, gelificantes, espumantes además de participar en la retención de agua y grasa.

Una de las alternativas para la utilización del suero es la elaboración de bebidas refrescantes, bebidas fermentadas y alcohólicas por sus bajos costos de producción y alto valor nutricional (Parra, 2009). Además, la goma xanthan es un heteropolisacárido con estructura primaria que consiste en unidades repetidas de pentasacárido, formado por dos unidades de glucosa, dos de manosa y una de ácido glucorónico. La agencia americana Food and Drug Administration (FDA) ha aprobado este polisacárido como aditivo alimentario puesto que varias investigaciones no han demostrado efectos adversos (García, Santos, Casas y Gómez, 2000). La función de un hidrocoloide es ligar agua, reaccionar con otros constituyentes del medio, estabilizar la red de proteína y evitar la liberación de agua (Soukoulis, Panagiotidis, Koureli y Tzia, 2007). En cuanto a sus propiedades fisicoquímicas, a un bajo $\mathrm{pH}$, la disolución de la goma es rápida y completa e influye en la suspensión de componentes insolubles. El uso de la goma en bebidas con frutas cítricas proporciona estabilización en las propiedades organolépticas, específicamente olor, sabor y textura (Akkarachaneeyakorn y Tinrat, 2015). La norma INEN 2337:2008 del Instituto Ecuatoriano de Normalización (INEN, 2008) define el néctar de fruta como un producto pulposo o no pulposo sin fermentar, pero susceptible de fermentación; es obtenido de la mezcla de jugo de fruta o pulpa, concentrados, sin concentrar o la mezcla de estos que provienen de una o más frutas con agua con o sin ingredientes endulzantes. Ya el Codex Alimentarius (2005) define al néctar de fruta como una bebida sin fermentar a la cual se añade agua, azúcares o edulcorantes. Componentes aromatizantes volátiles, sustancias aromáticas, pulpas y células procedentes del mismo tipo de fruta, pueden ser agregados. La industria de jugos y conservas de fruta forma parte de la agroindustria en el Ecuador que tiene un alto potencial agrícola por la diversidad de suelos y climas y por tanto, existen las condiciones favorables para poder cultivar varios productos como principales insumos en la industria de elaboración de bebidas y alimentos. En cuanto al clima del país, 
se considera muy favorable para el cultivo de varias frutas como maracuyá, piña, mango, duraznos, naranjas, mora y limón, para la elaboración de bebidas y néctares (Gualavisí, 2011). Las frutas cítricas como las naranjas tienen beneficios saludables y nutricionales; también son principales fuentes de vitamina $\mathrm{C}$ y otros ácidos orgánicos; alto contenido de fibra soluble (58\%) e insoluble (42\%); predominantemente se destacan $\alpha$-carotenos, $\beta$ carotenos y $\beta$-criptoxantina; elevada cantidad de zeaxantina y luteína y prominente proporción de compuestos fenólicos. Además, aporta cantidades moderadas de ácido fólico y calcio; la naranja presenta el mayor contenido de este mineral (Gil, 2010). El uso del suero lácteo en el desarrollo de nuevos productos alimenticios como néctares de frutas abriría la posibilidad de obtener productos con alto valor nutricional, además de contribuir al cuidado del ambiente. Su inserción en el mercado dependería de la percepción y aceptación de los consumidores. Para esto es importante encontrar la mejor combinación del suero lácteo con la fruta y un hidrocoloide que genere las propiedades que caracterizan a las bebidas y que puedan ser una nueva opción para el consumidor.

Este estudio tuvo como objetivos evaluar la utilización de suero ácido y goma xanthan en la elaboración de un néctar de naranja, considerando propiedades físico-químicas como acidez, $\mathrm{pH}$ y sólidos solubles. Además, analizar sensorialmente la aceptación del producto y la intención de compra de los consumidores.

\section{Metodología}

\subsection{Materia prima}

Se utilizó naranja dulce (Citrus sinensis $(L)$ Osbeck), leche cruda de vaca y goma xanthan. La naranja fue obtenida en la frutería "Paraíso de Eva" en Cumbayá y adquirida en el cantón Chone en la provincia de Manabí. La fruta de categoría I y calibre 4 cumplió con todos los requisitos mínimos que indica la norma para naranjas (INEN, 2004); es decir que su calidad y sus características eran buenas y propicias a su variedad con defectos leves. Se lavaron con agua potable, luego por inmersión en agua clorada de 50 partes por millón (ppm) durante 1-2 minutos, y finalmente enjuagadas en agua potable, ya que el remanente no debe superar los $5 \mathrm{ppm}$ de cloro residual libre para el tratamiento de frutas y hortalizas sin pelar (Garmendia y Vero, 2006). Asimismo, la leche entera cruda para la obtención del suero ácido se obtuvo de un comerciante informal. La goma xanthan fue suministrada por la empresa La Casa de los Químicos ubicada en Quito.

\subsection{Procedimiento}

El contenido mínimo de sólidos solubles $\left(4,5^{\circ}\right.$ Brix) del néctar corresponde al mínimo de aporte de jugo (50\%) (INEN, 2008). El jugo de naranja se obtuvo mediante un exprimidor eléctrico "Oster" para cítricos, y se midió sólidos solubles por el método refractométrico 983.17 de la Association of Official Agricultural Chemists (AOAC, 2012). Para la obtención del suero ácido, la leche fue pasteurizada a $72^{\circ} \mathrm{C}$ por 15 segundos garantizándose la eliminación de la enzima fosfatasa (Luquet, 1993). Se añadió ácido cítrico hasta alcanzar un $\mathrm{pH}$ de 5,4 para la precipitación de las proteínas (Arciniega, 2010). Se adicionó 5 gotas de cuajo líquido, marca CHY-MAX® de CHR HANSEN por cada litro de leche y se calentó a $42^{\circ} \mathrm{C}$. Se dejó reposar hasta la formación de la cuajada. Finalmente, el suero fue filtrado hasta eliminar los residuos para medir sólidos solubles mediante el método refractométrico 983.17 (AOAC, 2012). La cantidad de azúcar fue calculada con base en un balance de masa considerando los valores de sólidos solubles del jugo de naranja y suero ácido. La cantidad de goma xanthan usada para bebidas es de 0,1 y $0,5 \%$ (Gaviria, Restrepo y Suárez, 2009). El ácido cítrico se añadió hasta ajustar el pH a 3,5. El agua se determinó por diferencia para completar $100 \mathrm{~g}$ de producto (Tabla 1).

Los ingredientes de la formulación inicial (Tabla 1) se pesaron y fueron agregados al suero ácido $\left(55^{\circ} \mathrm{C}\right)$, homogenizando la mezcla dos veces en el equipo (FT9 Homogeniser 
Armfield Ltd Ringwood England) a 300 PSI. Por último, el producto fue pasteurizado a $72^{\circ} \mathrm{C}$, y envasado inmediatamente al vacío en envases de vidrio esterilizados.

Tabla 1. Formulación inicial

\begin{tabular}{|l|c|}
\hline Ingredientes & $\mathbf{g} / \mathbf{1 0 0} \mathbf{g}$ \\
\hline Suero ácido & $17.5^{\star}$ \\
\hline Jugo de naranja & 50.00 \\
\hline Agua & $26.33^{\star *}$ \\
\hline Sacarosa & 6.00 \\
\hline Goma xanthan & $0.15^{\star}$ \\
\hline Ácido cítrico & 0.025 \\
\hline
\end{tabular}

* La cantidad de suero ácido y goma xanthan cambian de acuerdo con los tratamientos estudiados en el diseño experimental

${ }^{* *}$ El agua en cada tratamiento hasta completar los $100 \mathrm{~g}$ de producto

\subsection{Diseño experimental}

Los tratamientos fueron dispuestos en un diseño completamente al azar (DCA), con arreglo factorial $2^{2}$ (suero ácido: $10 \%$ y $15 \%$; goma xanthan: $0,05 \%$ y $0,1 \%$ ) y 4 repeticiones. Los datos fueron analizados mediante el Análisis de Varianza (ANOVA) y prueba de Tukey con $5 \%$ de probabilidad. Los factores y sus niveles fueron determinados por pruebas preliminares con base en estudios realizados por Jiménez (2014).

En la Tabla 2 se muestran los tratamientos con sus combinaciones de diferentes porcentajes de suero ácido y goma xanthan. En la Tabla 3 se presentan las variables de respuesta, con cada uno de sus métodos, especificaciones y referencias bibliográficas.

Tabla 2. Tratamientos y Combinaciones

\begin{tabular}{|l|l|}
\hline Tratamientos & Combinaciones \\
\hline A & $10 \%$ de suero ácido; $0,05 \%$ de goma xanthan \\
\hline B & $10 \%$ de suero ácido; $0,1 \%$ de goma xanthan \\
\hline C & $15 \%$ de suero ácido; $0,05 \%$ de goma xanthan \\
\hline D & $15 \%$ de suero ácido; $0,1 \%$ de goma xanthan \\
\hline
\end{tabular}

${ }^{*}$ El agua completa en cada tratamiento los $100 \mathrm{~g}$ de producto

Tabla 3. Variables de respuesta

\begin{tabular}{|c|c|c|c|}
\hline Variable & Método & Especificación & Referencia \\
\hline $\begin{array}{l}\text { Acidez } \\
\text { (\% Ácido Cítrico) }\end{array}$ & $\begin{array}{l}\text { Acidez Titulable, } \\
\text { Norma INEN-ISO } \\
750: 2013 \\
(\text { INEN, 2013)* }\end{array}$ & $0,4-0,6 \%$ & $\begin{array}{l}\text { Cañizares, Bonaine, } \\
\text { Laverde, Rodriguez y } \\
\text { Méndez, } 2009\end{array}$ \\
\hline $\begin{array}{l}\text { Sólidos Solubles } \\
\left({ }^{\circ} \text { Brix }\right)\end{array}$ & $\begin{array}{l}\text { Refractométrico, } \\
983.17 \\
(\text { AOAC, 2012) }\end{array}$ & $11,2-11,8$ & $\begin{array}{l}\text { Codex Stan 247-2005 } \\
\text { Norma General del Codex } \\
\text { para Zumos (Jugos) y } \\
\text { Néctares de Frutas } \\
\text { (Codex, 2005) }\end{array}$ \\
\hline $\mathrm{pH}$ & $\begin{array}{l}\text { Potenciometría; } \\
\text { Norma INEN } \\
\text { 389:1985 (INEN, } \\
1985)^{\star}\end{array}$ & $<4,5$ & $\begin{array}{l}\text { NTE INEN 2337:2008 } \\
\text { JUGOS, PULPAS, } \\
\text { CONCENTRADOS, } \\
\text { NÉCTARES, BEBIDAS } \\
\text { DE FRUTAS Y } \\
\text { VEGETALES. } \\
\text { REQUISITOS (INEN, } \\
2008)^{*}\end{array}$ \\
\hline
\end{tabular}

*Instituto Ecuatoriano de Normalización (INEN)

${ }^{* *}$ Association of Official Agricultural Chemists (AOAC) 


\subsection{Ponderación}

Se realizó una ponderación otorgando valores de 3,2 y 1 , a las variables de respuesta. Los sólidos solubles $\left({ }^{\circ} \mathrm{Brix}\right)(3)$ son los más importantes porque influyen en las propiedades reológicas y la estabilización de los jugos y están relacionados con las cualidades organolépticas de olor y sabor, además pueden afectar la apariencia del producto por la sedimentación (Mothé y Correia, 2003). La norma NTE INEN 2337:2008 (JUGOS, PULPAS, CONCENTRADOS, NÉCTARES, BEBIDAS DE FRUTAS Y VEGETALES. REQUISITOS) indica que la acidez (2) es proporcionada por la fruta (INEN, 2008), y el pH (1) era una variable que se debía ajustar con lo especificado.

Evaluación Sensorial

Para evaluar el nivel de agrado del mejor tratamiento se aplicó una escala hedónica de 5 puntos (5 "Gusta mucho", 1 "Me disgusta mucho", 3 como un valor intermedio "Ni me gusta, ni me disgusta") (Moskowitz, Beckley y Resurreccion, 2012). El número suficiente de jueces no entrenados para esta prueba es de 75, en el presente estudio participan 76. Los jueces fueron estudiantes, 43 mujeres y 33 hombres (entre 17 y 25 años) que evaluaron el nivel de agrado y la intención de compra del tratamiento presentado. La prueba se realizó en el aula sensorial de Ingeniería de Alimentos de la Universidad San Francisco de Quito.

Los panelistas fueron ubicados en cubículos individuales y recibieron el formulario respectivo y $40 \mathrm{~mL}$ de néctar de naranja a una temperatura de $12^{\circ} \mathrm{C}$ (Meilgaard, Civille y Carr, 2006), en vasos transparentes de polipropileno (5.5 oz) con la codificación 373. Además del nivel de agrado los jueces respondieron si comprarían o no el néctar. Los datos obtenidos fueron analizados estadísticamente.

\section{Resultados}

Se observaron diferencias significativas en \% de acidez y contenido de sólidos solubles, pero no en el $\mathrm{pH}$ de los tratamientos (Tabla 4).

Tabla 4. Resumen de Análisis de Varianza (ANOVA) de pH, Acidez y Sólidos Solubles de los tratamientos

\begin{tabular}{|l|c|c|c|c|}
\hline \multirow{2}{*}{$\begin{array}{l}\text { Fuentes } \\
\text { Variación }\end{array}$} & \multirow{2}{*}{ GL } & \multicolumn{3}{|l|}{ Cuadrados Medios } \\
\cline { 3 - 5 } & & $\mathbf{p H}$ & $\begin{array}{l}\text { Acidez } \\
\text { (\% Ácido Cítrico) }\end{array}$ & $\begin{array}{l}\text { Sólidos } \\
\text { Solubles } \\
\text { ('Brix) }\end{array}$ \\
\hline Total & 15 & & & $3,066^{*}$ \\
\hline Tratamientos & 3 & $0,005^{\text {n.s. }}$ & $0,008^{*}$ & $2,806^{*}$ \\
\hline A (Suero) & 1 & $0,001^{\text {n-s. }}$ & $0,001^{\text {n.s. }}$ & $0,016^{\text {n.s. }}$ \\
\hline B (Goma) & 1 & $0,003^{\text {n.s. }}$ & $0,004^{*}$ & $6,376^{*}$ \\
\hline Interacción A x B & 1 & $0,012^{*}$ & $0,020^{*}$ & $0,011^{*}$ \\
\hline Error Exp. & 12 & 0,002 & 0,001 & \\
\hline
\end{tabular}

${ }^{*}$ Significativo al $5 \%$ de probabilidad por la prueba de $\mathrm{F}$.

n.s. No significativo al $5 \%$ de probabilidad por la prueba $\mathrm{F}$

La Tabla 5 muestra los valores de $\mathrm{pH}$ de los tratamientos que cumplieron con los requisitos de la norma NTE INEN 2337:2008 (JUGOS, PULPAS, CONCENTRADOS, NÉCTARES, BEBIDAS DE FRUTAS Y VEGETALES. REQUISITOS), que señala que el $\mathrm{pH}$ de un néctar de fruta debería ser menor a 4,5 (INEN, 2008).

El Análisis de Varianza (Tabla 4) muestra que la adición de suero ácido no influyó significativamente en la acidez de los tratamientos; mientras que la goma xanthan y la interacción de los factores si afectaron.

Como se observa en la Tabla 6, con excepción del tratamiento $\mathrm{C}$, todos los tratamientos cumplieron con el porcentaje de acidez para néctar $(0,4-0,6 \%)$ establecido según Cañizares et al. (2009). 
Tabla 5. pH de los tratamientos

\begin{tabular}{|l|l|}
\hline Tratamientos & $\mathrm{pH}^{*}$ \\
\hline $\mathrm{A}$ & $3,54 \pm 0,03$ \\
\hline $\mathrm{B}$ & $3,53 \pm 0,01$ \\
\hline $\mathrm{C}$ & $3,50 \pm 0,05$ \\
\hline $\mathrm{D}$ & $3,59 \pm 0,08$ \\
\hline \multicolumn{2}{|l}{} \\
\multicolumn{2}{|l}{} \\
\multicolumn{2}{|l|}{ *Medias $\pm \mathrm{DS}$}
\end{tabular}

Tabla 6. Acidez de los tratamientos expresado en porcentaje de ácido cítrico

\begin{tabular}{|l|l|}
\hline Tratamientos & $\begin{array}{l}\text { Acidez } \\
\text { (\% Ácido Cítrico) }\end{array}$ \\
\hline C & $0,61 \pm 0,003 \mathrm{a}$ \\
\hline $\mathrm{B}$ & $0,59 \pm 0,005 \mathrm{~b}$ \\
\hline $\mathrm{A}$ & $0,55 \pm 0,032 \mathrm{C}$ \\
\hline $\mathrm{D}$ & $0,51 \pm 0,003 \mathrm{~d}$ \\
\hline \multicolumn{2}{l}{} \\
\hline
\end{tabular}

${ }^{*}$ Medias seguidas por las mismas letras no difieren entre si al $5 \%$ de la probabilidad por la prueba de Tukey

La adición de suero ácido y la interacción de los factores afectaron significativamente a los sólidos solubles de los tratamientos, mientras que la goma xanthan no tuvo influencia (Tabla 7). En la Tabla 8 se muestra el contenido de sólidos solubles. Acorde con la norma Codex Stan $247(11,2-11,8)$ (Codex, 2005), el tratamiento B fue el único que cumplió con el requerimiento. No obstante, en los cuatro tratamientos se observó separación de fases que pudo ser ocasionada por la carga del polisacárido, pudiendo interactuar con las proteínas mediante fuerzas electrostáticas (Azarikia y Abbasi, 2010). Souza y García-Rojas (2017) observaron que a medida que aumentaba la relación proteína / polisacárido, complejos insolubles se formaban en un $\mathrm{pH}$ por encima del punto isoeléctrico de la proteína. En el presente estudio a mayor cantidad de goma xanthan $(0,1 \%)$ fue menor el contenido de sólidos solubles $(p \leq 0,5)$ como se observa en los tratamientos B y D (Tabla $7)$.

Tabla 7. Sólidos solubles de los tratamientos

\begin{tabular}{|l|l|}
\hline Tratamientos & $\begin{array}{l}\text { Sólidos Solubles } \\
\left({ }^{*} \text { Brix }\right)\end{array}$ \\
\hline A & $12,98 \pm 0,10 \mathrm{a}$ \\
\hline $\mathrm{C}$ & $12,08 \pm 0,10 \mathrm{~b}$ \\
\hline $\mathrm{B}$ & $11,65 \pm 0,10 \mathrm{c}$ \\
\hline $\mathrm{D}$ & $10,88 \pm 0,13 \mathrm{~d}$ \\
\hline
\end{tabular}

*Medias seguidas por las mismas letras no difieren entre si al 5\% de la probabilidad por la prueba de Tukey

Los datos de $\mathrm{pH}$, acidez y sólidos solubles presentaron coeficientes de variación de $1,37 \%, 3,04$ y $0,88 \%$ respectivamente y mostraron confiabilidad y aceptabilidad, para experimentación en laboratorio (10\%) (Sánchez, 2009).

La mayoría de los tratamientos cumplió con las especificaciones de $\mathrm{pH}$ y porcentaje de acidez, sin embargo solo el tratamiento $B$ mantuvo lo indicado para sólidos solubles, fue además el mejor tratamiento ( 6 puntos en la ponderación final) a diferencia del tratamiento C que presentó el menor valor (2 puntos).

\subsection{Evaluación sensorial}

El tratamiento $B$ mostró una media final de 4,17, ubicándose entre las categorías "Me gusta" y "Me gusta mucho" que fueron las de mayor frecuencia (26 y 39 respectivamente). 
El $51 \%$ de los jueces no entrenados calificó al producto como "Me gusta", seguido por el $34 \%$ "Me gusta mucho". El producto tuvo un nivel de agrado del $85 \%$. Además, el $86 \%$ compraría el producto, y el $14 \%$ no.

\subsection{Formulación final}

En la Tabla 8 se muestra la formulación final (tratamiento B) con relevancia en suero ácido, goma xanthan y jugo de naranja.

Tabla 8. Formulación final

\begin{tabular}{|l|c|}
\hline Ingredientes & $\mathbf{g} / \mathbf{1 0 0} \mathbf{~ g}$ \\
\hline Suero ácido & 10,00 \\
\hline Jugo de naranja & 50,00 \\
\hline Agua & 33,88 \\
\hline Azúcar & 6,00 \\
\hline Goma xanthan & 0,10 \\
\hline Ácido cítrico & 0,025 \\
\hline
\end{tabular}

\section{Discusión}

En el presente estudio diferentes concentraciones de goma xanthan no influyeron en el $\mathrm{pH}$ de los tratamientos (tablas 4, 5). Las gomas son muy estables con respecto a las variaciones de $\mathrm{pH}$. Se implementan como estabilizantes que forman dispersiones tixotrópicas, al dispersarse en agua, producir viscosidad en el medio y otorgar una buena estabilidad y rápida solubilidad a bajo pH (Sharma, Narres y Dhuldhoya, 2006). También, García et al. (2000) señalaron que ni el pH ni la temperatura influyeron en las propiedades reológicas de la goma; sin embargo, con un $\mathrm{pH}$ menor a 3, puede haber pérdidas de grupos pirúvicos. Como se observa en la Tabla 5 el pH de los tratamientos estuvo entre 3,50 y 3,59. En cuanto al suero ácido, algunos autores concuerdan que el $\mathrm{pH}$ influye en las propiedades de la proteína de suero, pues tiene una carga positiva a un pH menor que el punto isoeléctrico $(5,2)$ comportándose como un catión (Gangurde et al., 2011), con aumento de la solubilidad y disminución de la turbidez (LaClair \& Etzel, 2010; Park, Bastian, Farcas, \& Drake, 2014).

Según Gaspoz (2008) las interacciones entre proteínas y polisacáridos pueden ser repulsivas o atractivas, ocurre una interacción atractiva entre la proteína cargada positivamente y la goma con carga negativa, por debajo del punto isoeléctrico de las proteínas en valores ácidos de $\mathrm{pH}$; Durante el desarrollo del néctar el $\mathrm{pH}$ de los tratamientos estuvo en la escala ácida (3,50 a 3,59); en valores alcalinos se da una interacción repulsiva debido a las cargas negativas de ambos complejos electrostáticos. Capitani, Baeza, Pilosof y Bertoldo-Pacheco (2003) observaron que a pH por debajo de 5,4 y 4,6, se formaron complejos del polisacárido carboximetilcelulosa, con proteínas totales y fraccionadas, es el complejo más efectivo a pH ácido. Otro estudio realizado por Gaspoz (2008) determinó un aumento en la fuerza iónica, la relación polisacárido-proteína y en las fuerzas atractivas entre el polisacárido-proteína, cuando el pH descendió.

En la presente investigación el suero ácido no afectó la acidez de los tratamientos, mientras que la concentración de goma y la interacción suero-goma influyeron significativamente $(p \leq 0.05)$. Los estabilizantes son sensibles y responsables de la acidez del sistema (Gaviria et al., 2009). La inclusión de estabilizantes induce significativamente la concentración de acetaldehído. Es por esto que los yogures con estabilizantes requieren menos tiempo de incubación. Además, los hidrocoloides pueden tener grupos aniónicos y catiónicos que reaccionan con partículas que se encuentran en la leche como proteínas o iones de calcio (Soukoulis et al., 2007).

Soukoulis et al. (2007) al analizar la fermentación y las mejoras de yogurt con diferentes tipos de proteínas e hidrocoloides, observaron que la goma xanthan previno los 
efectos del suero de leche; sin embargo, la alta temperatura afectó a la viscosidad. Al coincidir con el estudio de Jiménez (2014) sobre la adición de biopolímeros en un jugo de maracuyá, para analizar la estabilidad fisicoquímica y antioxidante, cuando se usó $0,1 \%$ de goma xanthan, la acidez fue de $0,58 \%$, ocurrió un incremento de la acidez a mayor porcentaje de la goma xanthan. En el néctar desarrollado en el presente estudio la acidez en los tratamientos con $0,1 \%$ de goma xanthan fue 0,51 y 0,59 (tratamientos $D$ y $B$ respectivamente).

Baljeet, Ritika y Sarita (2012) al elaborar una bebida de frutas con suero de leche, encontraron que la piña afectó más en el nivel de acidez, que el suero ácido, lo que coincide con los resultados obtenidos en esta investigación ya que según la Tabla 4, las concentraciones de suero no afectaron significativamente la acidez de los tratamientos.

La interacción de suero y goma se ve afectada por la sedimentación de sólidos y la separación de suero de leche en el envase; sin embargo, para evitar este defecto se usan hidrocoloides que, al prevenir esta separación, aumentan la viscosidad de la fase atrapando el agua en una red, e inmovilizando las partículas del sistema; además pueden interactuar con las proteínas del suero mediante fuerzas electrostáticas (Azarikia y Abbasi, 2010). La goma xanthan crea una suspensión de componentes insolubles para que interactúen con los componentes del sistema; esto ocurre por la rápida solubilidad y completa disolución a un pH bajo (Akkarachaneeyakorn y Tinrat, 2015). Jiménez (2014) determinó $13,86^{\circ}$ Brix al usar $0.1 \%$ de la goma, al elaborar una bebida de maracuyá, suero de leche y goma xanthan. En la presente investigación los tratamientos con $0,1 \%$ y $0,05 \%$ de goma xanthan además de jugo de naranja y suero de leche tuvieron grados Brix entre 10,88 y 12,98. El análisis de varianza (Tabla 4) del presente estudio mostró la influencia significativa del suero y de la interacción goma xanthan-suero en esta variable de respuesta.

Igualmente, en bebidas se aprovechan las concentraciones altas de lactosa en el suero, la cual se puede descomponer en galactosa y glucosa (Vaclavik y Christian, 2002). Durante la elaboración de una bebida hidratante con lactosuero, se observó que los grados Brix aumentaban de forma proporcional a la cantidad de lactosuero (Chóez y Morales, 2011). Esto no fue observado en la presente investigación ya que los tratamientos (A, B) con menor contenido de suero (10\%) presentaron los valores más altos de grados Brix diferentes significativamente entre si $(p \leq 0,05)$ y con los tratamientos que tenían mayor contenido de lactosuero (15\%), lo que puede deberse al efecto de la goma xanthan ya que la interacción de estos dos factores (suero ácido y goma xanthan) influyó significativamente en los grados Brix de los tratamientos.

Dentro de los comentarios negativos de la formulación final (Tratamiento B) los hombres indicaron que el sabor estaba muy dulce y artificial, detectaron regusto y falta de intensidad en el color y aroma. Para las mujeres, la percepción fue muy similar además de que les pareció muy espeso. Sin embargo, al calificar al producto de forma global dentro de la escala hedónica el nivel de agrado fue alto igual que la intención de compra. Esto indicó que aunque algunos atributos no fueron del agrado de los jueces la percepción global del néctar fue favorable y no impidió su aceptación.

\section{Conclusiones y recomendaciones}

Se estableció la relación adecuada de suero ácido y goma xanthan en la elaboración de néctar de naranja. El único tratamiento (B) que cumplió con todas las características requeridas por la legislación vigente fue el formulado con $10 \%$ de suero ácido y $0,1 \%$ de goma xanthan. La adición de goma xanthan solo influyó en la acidez, el suero ácido en los grados Brix, pero ninguno de estos factores afectó el pH de los tratamientos. Además en la prueba sensorial tuvo un nivel de aceptación del $85 \%$, con una media de 4,17 (categorías "Me gusta" y "Me gusta mucho") y presentó una intención de compra del 86\%. 
El néctar cumplió con las características tanto físico-químicas como organolépticas e indicó que sí es posible la utilización de suero ácido y goma xanthan para la elaboración de este producto.

Para evitar la separación y mejorar la estabilidad en los jugos de frutas es necesario la mezcla de dos estabilizantes. En el presente trabajo se determinó la concentración requerida de goma xhantan para lograr estabilidad. Es importante determinar en futuras investigaciones la viscosidad, turbidez y separación de fases en bebidas con suero de leche.

\section{Bibliografía}

Akkarachaneeyakorn, S., y Tinrat, S. (2015). Effects of types and amounts of stabilizers on physical and sensory characteristics of cloudy ready-to-drink mulberry fruit juice. Food Science and Nutrition, 3(3), 213-220. doi:10.1002/fsn3.206.

Arciniega, A. C. (2010). Evaluación de ácido cítrico y láctico en la elaboración de Queso Mozarella. Escuela Agrícola Panamericana El Zamorano, Ingeniera en Agroindustria Alimentaria en el Grado, Honduras. Recuperado el 15 de octubre de 2015, de http://bdigital.zamorano.edu/bitstream/11036/228/1/T2902.pdf

Azarikia, F., y Abbasi, S. (2010). On the stabilization mechanism of Doogh (Iranian yoghurt drink) by gum tragacanth. Food Hydrocolloids, 24(4), 358-363. doi:10.1016 /j.foodhyd.2009.11.001

Baljeet, S., Ritika, B., y Sarita, R. (2012). Studies on development and storage of wheybased pineapple (Ananas comosus) and bottle gourd (Lagenaria siceraria) mixed herbal beverage. International Food Research Journal, 20(2), 607-612.

Cañizares, A., Bonaine, O., Laverde, D., Rodriguez, R., y Méndez, J. (2009). Caracterización química y organoléptica de néctares a base de frutas de lechosa, mango, parchita y lima. UDO Agrícola, 1(9), 74-79. Obtenido de http://udoagricola.orgfree.com/V9N1UDOAg/V9N1Canizares74.htm

Capitani, C., Baeza, R., Pilosof, A., y Bertoldo-Pacheco, M. (2003). Propiedades de espumado de complejos de proteínas del lactosuero y carboximetilcelulosa. En J. Girón, Proteínas Alimentarias y coloides de interés industrial (págs. 159-169). Sevilla: JIPAC.

Chandrapala, J., Duke, M., Gray, S., Zisu, B., Weeks, M., Palmer, M., y Vasiljevic, T. (2015). Properties of acid whey as a function of $\mathrm{pH}$ and temperature. Journal of Dairy Science, 98(7), 4352-4363. doi:10.3168/jds.2015-9435.

Chóez, J., y Morales, M. (2011). Elaboración de una bebida hidratante a base de lactosuero y enriquecida con vitaminas. Escuela Superior Politécnica del Litoral, Facultad de Ingeniería en Mecánica y Ciencias de la Producción, Guayaquil. Recuperado el 18 de noviembre de 2015, de http://www.dspace.espol.edu.ec/handle/123456789/14850

Codex. (2005). Norma General del Codex para Jugos y Néctares de Frutas. Codex Stan 247.

Gangurde, H., Chordiya, M., Patil, P., y Baste, N. (2011). Whey Protein. Scholars Research Journal, 1(2), 69-77. doi:10.4103/2249-5975.99663.

García, F., Santos, V., Casas, J., y Gómez, E. (2000). Xanthan gum: production , recovery, and properties. Biotechnology Advances, 18(7), 549-579. doi:10.1016/S07349750(00)00050-1

Garmendia, G., y Vero, S. (2006). Métodos para la desinfección de frutas y hortalizas. Horticultura. Tecnología de postcosecha(197), 18-27.

Gaspoz, J. (2008). Diseño de biomateriales por coacervación de proteínas de suero lácteo y alginato de sodio: efecto del ph y fuerza iónica. Asociación Argentina de Materiales. Obtenido de http://www.materiales-sam.org.ar/sitio/biblioteca/jovenesSAM08 /Trabajos_completos/11.Biomateriales/11112\%20GaspozJ.pdf 
Gaviria, P., Restrepo, D., y Suárez, H. (2009). Utilización de Hidrocoloides en bebida láctea tipo Kumis. Vitae, 17(1), 29-36. Obtenido de http://www.redalyc.org /articulo.oa?id=169815395004

Gil, A. (2010). Tratado de Nutrición. Composición y Calidad Nutritiva de los Alimentos (Segunda Edición ed.). Madrid, España: Editorial Médica Panamericana.

Gualavisí, M. (2011). Elaboración de jugos y conservas de frutas. Flacso-Mipro, Centro de Investigaciones Económicas de la Pequeña y Mediana Industria, Quito, Ecuador. Recuperado el 22 de octubre de 2015, de https://www.flacso.edu.ec/portal /pnTemp/PageMaster/f3aum4sgz8ls6rsximf6khej5eeefz.pdf

Instituto Ecuatoriano de Normalización. (2004). NORMA PARA LA NARANJA. Quito: Norma Técnica Ecuatoriana. NTE INEN 2844.

Instituto Ecuatoriano de Normalización. (2008). JUGOS, PULPAS, CONCENTRADOS, NÉCTARES, BEBIDAS DE FRUTAS Y VEGETALES. REQUISITOS. Quito: Norma Técnica Ecuatoriana. NTE INEN 2337.

Jelen, P. (2003). Whey processing. Utilization and Products. 2739-2745. In: H. Roginski, J.W. Fuquay and P.F. Fox (eds.). Encyclopedia of Dairy Sciences. Academic Press, London, UK.

Jiménez, J. (2014). Efecto de la adición de biopolímeros sobre la estabilidad físicoquímica y antioxidante de jugo de maracuyá (Passiflora edulis var. flavicarpa). Veracruz, México. Recuperado el 30 de noviembre de 2015, de http://cdigital.uv.mx/bitstream /123456789/38577/1/JimenezSolano.pdf

LaClair, C., y Etzel, M. (2010). Ingredients and pH are key to clear beverages that contain whey protein. Journal of Food Science, 75(1), 21-27. doi:10.1111/j.17503841.2009.01400.x

Londoño, M., Sepúlveda, J., Hernández, A., y Parra, J. (2008). Bebida fermentada de suero de queso fresco inoculada con Lactobacillus casei. Revista Facultad Nacional de Agronomía, 61(1), 4409-4421.

Luquet, F. (1993). Leche y Productos Lácteos - Vaca, Obeja, Cabra (Segunda Edición ed.). Zaragoza, España: Acribia S.A.

Meilgaard, M., Civille, G., y Carr, T. (2006). Sensory evaluation of techniques (Cuarta Edición ed.). Detroit, Estados Unidos: CRC Press. Taylor \& Francis Group.

Moskowitz, H., Beckley, J., y Resurreccion, A. (2012). Sensory and consumer research in food product design and development (Segunda Edición ed.). lowa, USA: John Wiley \& Sons.

Mothé, C. G., \& Correia, D. Z. (2003). Rheological properties of cashew/xanthan gums blends in cashew juice. En 3rd Int Symposium on Food Rheology and Structure, ETH, Zurich, Suiza.

Muñi, A., Páez, G., Faría, J., Ferrer, J., y Ramones, E. (2005). Eficiencia de un sistema de ultrafiltración/nanofiltración tangencial en serie para el fraccionamiento y concentración de lactosuero. Revista Científica, 15(4), 361-367. Obtenido de http://www.redalyc.org/pdf/959/95915410.pdf

Official Method of Analysis of AOAC International. (2012). Official Method of Analysis of AOAC International (19th ed., Vol. II). (G. Latimer, Ed.) Maryland: AOAC INTERNATIONAL.

Park, C., Bastian, E., Farcas, B., y Drake, M. (2014). The effect of acidification of liquid whey protein concentrate on the flavor of spray-dried powder. Journal of Dairy Science, 97(7), 4043-4051. doi:10.3168/jds.2013-7877

Parra, R. (Abril de 2009). Lactosuero: importancia en la Industria de Alimentos. Revista Facultad Nacional de Agronomía, 62(1), 4967-4982.

Sánchez, J. C. (2009). Introducción al Diseño Experimental. Quito, Ecuador: Cámara Ecuatoriana del Libro.

Sharma, B., Narres, L., y Dhuldhoya, N. (2006). Xanthan gum-A boon to food industry. Food Promotion Chronnicle, 1(5), 27-30. 
Soukoulis, C., Panagiotidis, P., Koureli, R., y Tzia, C. (2007). Industrial Yogurt Manufacture: Monitoring of Fermentation Process and Improvement of Final Product Quality. Journal of Dairy Science, 90(6), 2641-2654. doi:10.3168/jds.2006-802

Souza, C., García-Rojas, E. (2017). Interpolymeric complexing between egg white proteins and xanthan gum: Effect of salt and protein/polysaccharide ratio. Food Hydrocolloids, 66, 268-275. doi: 10.1016/j.foodhyd.2016.11.032

Vaclavik, V., y Christian, E. (2002). Fundamentos de Ciencia de los Alimentos. Zaragoza: Acribia.

Vela, G., Castro, M., Caballero, A., y Ballinas, J. (2012). Bebida probiótica de lactosuero adicionada con pulpa de mango y almendras sensorialmente aceptable por adultos mayores. Revista de la Ciencia, Tecnología e Ingeniería de los Alimentos, 11(2), 920. 